\title{
Interactive comment on "The Impact of Volcanic Eruptions of Different Magnitude on Stratospheric Water Vapour in the Tropics” by Clarissa Alicia Kroll et al.
}

\section{Olivier Boucher}

olivier.boucher@Imd.jussieu.fr

Received and published: 6 December 2020

Thank you for posting this interesting study. It may be useful to make the link with the literature on stratospheric aerosol injection. In Boucher et al. (2017), we showed that stratospheric water vapour (SWV) responds to aerosol heating in the tropical tropopause layer. We also quantified the contribution of this fast adjustment to the effective radiative forcing by stratospheric aerosols. For $10 \mathrm{Tg} \mathrm{S} \mathrm{yr}^{-1}$ emitted as $\mathrm{SO}_{2}$ at $17 \mathrm{~km}$ altitude, we found a radiative effect from SWV of $+0.19 \mathrm{Wm}^{-2}$, which represents $7.2 \%$ of the ERF or $13.2 \%$ of the IRF (see Table 1 in Boucher et al., 2017). Note that the radiative effect from the stratospheric heating itself is larger. I suspect however 
the heating due to stratospheric aerosols in our model to be too high.

Boucher, O., C. Kleinschmitt, and G. Myhre, Quasi-additivity of the radiative effects of marine cloud brightening and stratospheric aerosol injection, Geophysical Research Letters, 44, 11158-11165, doi: 10.1002/2017gl074647, 2017.

Interactive comment on Atmos. Chem. Phys. Discuss., https://doi.org/10.5194/acp-2020-1191, 2020. 